\title{
WHEN CONSUMERS DO NOT MAKE AN ACTIVE DECISION: DYNAMIC DEFAULT RULES AND THEIR EQUILIBRIUM EFFECTS
}

Keith M. Marzilli Ericson

Working Paper 20127

http://www.nber.org/papers/w20127

\author{
NATIONAL BUREAU OF ECONOMIC RESEARCH \\ 1050 Massachusetts Avenue \\ Cambridge, MA 02138
}

May 2014

Portions of this paper were previous circulated as part of "Market Design when Firms Interact with Inertial Consumers: Evidence from Medicare Part D". I thank Raj Chetty, David Cutler, Stefano DellaVigna, Drew Fudenberg, Andreas Fuster, Larry Katz, David Laibson, Michael Grubb, Oliver Hart, Jim Rebitzer, Michael Salinger, Amanda Starc, and participants at the 2013 European Behavioral Economics Meeting for their thoughtful comments. I thank the Williams College Tyng Committee and the National Science Foundation for research support. The views expressed herein are those of the author and do not necessarily reflect the views of the National Bureau of Economic Research.

NBER working papers are circulated for discussion and comment purposes. They have not been peerreviewed or been subject to the review by the NBER Board of Directors that accompanies official NBER publications.

(C) 2014 by Keith M. Marzilli Ericson. All rights reserved. Short sections of text, not to exceed two paragraphs, may be quoted without explicit permission provided that full credit, including $\odot$ notice, is given to the source. 
When Consumers Do Not Make an Active Decision: Dynamic Default Rules and their Equilibrium Effects

Keith M. Marzilli Ericson

NBER Working Paper No. 20127

May 2014

JEL No. D01,D02,D03,D04,D81,D86,H23,L1

\begin{abstract}
$\underline{\text { ABSTRACT }}$
Dynamic defaults for recurring purchases determine what happens to consumers enrolled in a product or service who take no action at a decision point. Consumers may face automatic renewal, automatic switching, or non-purchase defaults. Privately optimal dynamic defaults depend on the contributions of adjustment costs versus psychological factors leading to inaction: both produce inertia under renewal defaults, but differ under non-renewal defaults. Defaults have equilibrium effects on pricing by changing the elasticity of repeat demand. Socially optimal defaults depend on firms' pricing responses as well; more elastic repeat demand restrains price increases on repeat customers and can reduce inefficient switching.
\end{abstract}

Keith M. Marzilli Ericson

Boston University School of Management

595 Commonwealth Avenue

Boston, MA 02215

and NBER

kericson@bu.edu 


\section{Introduction}

Defaults determine what happen to consumers who do not actively express a preference. This paper examines a previously unstudied category of default - "dynamic defaults" for recurring purchases of products or services. Products purchased on a flow or subscription basis are ubiquitous, and such products have dynamic defaults: defaults that determine whether a consumer who previously purchased the product will continue to purchase the product if they do not make an active decision. This paper shows how these defaults affect firm behavior and how they can be optimally set.

This paper provides a model to describe consumer behavior under dynamic defaults, and shows how optimal dynamic defaults depend on both the source of individual inertia and on how firms respond to them. It is well known that one-time assignment default rules can have powerful effects on individual behavior in many contexts, from retirement savings behavior (Madrian and Shea 2001; Choi, Laibson, Madrian and Metrick 2004; Goda and Manchester 2013) to organ donation (Johnson and Goldstein 2003; Abadie and Gay 2004). Yet defaults do not merely affect individual behavior: they also have equilibrium effects. This paper is the first to examine optimal defaults in markets where firms strategically interact with individuals. ${ }^{1}$ The model shows how defaults have externalities, as the defaults consumers would choose for themselves do not necessarily correspond to the socially optimal default. Hence, market designers may desire to intervene and set market-wide defaults, such as employers administering retirement funds, health insurance exchanges, and utility regulators offering consumer choice of electricity prices.

Policy-makers have attempted to determine how dynamic defaults can best be set, but they have lacked an analytic framework to guide their choice, as the economics literature has not examined dynamic defaults for recurring purchases of products or services. Consider the Medicare Part D prescription drug insurance market, a large and controversial program that is also a model for other health insurance exchanges. ${ }^{2}$ Prices for insurance plans vary from year to year, and individuals can switch between plans each year. Policy-makers debated ${ }^{3}$ which dynamic default should apply to low-income individuals: should they be automatically renewed in their current plan, or automatically switched to a similar, cheaper plan? They

\footnotetext{
${ }^{1}$ Note that one-time assignment default rules can have equilibrium effects as well, as they can change the price elasticity of demand that firms face.

${ }^{2}$ Medicare Part D provides prescription drug insurance for the elderly. In contrast to traditional Medicare, it relies on a competitive market of firms that offer prescription drug insurance plans. It receives government subsidies of about $\$ 40$ billion annually and covers over 24 million people. For more detail on the program in general, see Duggan, Healy, and Scott Morton (2008). For more detail on its defaults, inertia, the low-income subsidy program, see Ericson (2014a).

${ }^{3}$ See e.g. Centers for Medicare and Medicaid Services (2009); Summer, Hoadley and Hargrave (2010).
} 
were concerned that low-income individuals would be inattentive, and be exploited by firms raising prices on them in later years. Automatic switching has potential benefits to enrollees - those who are switched save money - but could also be harmful if enrollees faced costs of switching plans, such as missed prescriptions. Ultimately, these low-income enrollees were given an automatic switching default: if their plan raised its price above a benchmark threshold, they had to actively send in a form to reenroll in their current plan, or else they would be automatically switched to one of the cheapest plans in the market. In contrast, higher-income enrollees received an automatic renewal default, in which they stayed in their plan unless they actively chose otherwise. ${ }^{4}$

Products purchased on a flow or subscription basis are prevalent in core sectors of the economy, including healthcare (insurance, prescription drug refills), finance (banking and investment services, credit cards, auto and life insurance), energy (electricity and natural gas), telecommunications (cell phones, cable, internet), software (consumers and firms can subscribe to cloud-based software applications such as Microsoft Office and Adobe Creative Suite), and consumer products (for instance, online retailer Amazon.com has a program in which consumers can subscribe to period deliveries of various items, such as food or batteries).

In each case, consumers enroll in a product or service at a specified price. However, these markets do not typically feature long-term price commitment, so firms can later update their prices. Consumers can then either actively switch to a different product/service (or to no product), actively choose to stay with their current product/service, or simply do nothing. For instance, consumers can choose to renew their current health insurance plan or switch plans during the annual open enrollment period. Banks and credit card companies alter fee structure and contracts, and consumers could actively affirm their acceptance of the new terms or switch to a competing firm. However, consumers often simply take no action.

Dynamic defaults determine what happens to consumers who previously purchased a product or service if they take no action at a decision point. In many cases, customers who do nothing are automatically renewed with their current service provider, regardless of the provider's new price. Such automatic renewal defaults can make repeat demand less price elastic, and thereby enable firms to raise prices on consumers who face high adjustment costs or who are inattentive. This leads to inefficient churning of consumers between products, as they switch to get a better deal. In other contexts, consumers face non-renewal defaults that would require them to make an active decision to continue purchasing their current product

\footnotetext{
${ }^{4}$ The Massachusetts Group Insurance Commission (health insurance for state employees) provides another example of a dynamic switching default: in 2011, individuals who did not make an active choice were by default automatically switched to the cheapest plan unless they made an active choice.
} 
or service if the firm has raised prices. Under an automatic switching default, failure to act leads consumers to be switched to an alternative product if their current provider has raised prices (e.g. a cheaper electricity supplier); under a non-purchase default, consumers receive no product at all if they do not act (e.g. not renewing a magazine subscription).

Dynamic defaults matter because individuals display inertia - they tend to avoid making an active decision and are likely to stick with past choices, even though they would make a different choice if they were choosing for the first time. Often the failure of individuals to switch products to take advantage of cheaper alternatives has been interpreted as switching costs or adjustment costs (e.g. Greenstein's (1993) study of computer systems; Chetty et al. (2011) on labor supply). Adjustment costs are prevalent and impact behavior in many domains. Yet the literature also shows substantial inertial behavior even when the costs of switching seem much smaller than gains. In employer-provided health insurance, Handel (2013) examined choice following a large price change and finds that individuals may have forgone gains of approximately $\$ 2000$ that year to stay in their current plan, even though the alternative option was offered by the same firm, had identical networks, and could be switched to by mailing in a simple form. ${ }^{5}$ Madrian and Shea (2001) examine retirement savings plans, and find that initial enrollment defaults that do not require employees to send in a form have economically significant effects on retirement savings; Chetty et al. (2012) show that defaults have significant effects on wealth accumulation. Moreover, Esteves-Sorenson and Perretti (2011) find evidence of non-trivial inertia even when adjustment costs are tiny changing a television channel.

Distinguishing between two types of frictions is necessary to set optimal dynamic defaults: real adjustment (switching) costs and psychological factors that lead to inaction (PFLIs). Both types of frictions lead to inertia under automatic renewal defaults, but they differ in their implications for welfare and for the effects of non-renewal defaults. Adjustment costs are the time and effort costs that result from moving between products, e.g., setting up new paperwork or learning how a new product or service operates. However, psychological factors can also lead individuals to fail to act, even if switching products is not costly: e.g. inattention (Lacetera, Pope, and Sydnor 2012), procrastination (O'Donoghue and Rabin 2001), and limited memory (Ericson 2011). For instance, individuals can forget to send back a form, even if sending the form is not itself costly. If individuals are inactive because they are forgetful but do not face large adjustment costs, an automatic switching default can make them better off by switching them to cheaper services of equivalent quality.

\footnotetext{
${ }^{5}$ A number of other studies document inertia in health insurance choice, including Samuelson and Zeckhauser's (1988) classic paper status quo bias, and Strombom, Buchmueller and Feldstein's (2002) examination of employer-based health insurance enrollment.
} 
On the other hand, if individuals face large adjustment costs but still forget to opt out of the default, automatic switching can make them worse off.

The analysis of dynamic defaults requires a model of firm pricing behavior. Because defaults affect individual behavior, they change the incentives facing firms and thereby alter firms' pricing strategy. Inertia implies that potential repeat customers are less price-sensitive than potential new customers. As a result, prices are often lower for first-time buyers than for consumers already enrolled in a subscription product or service: firms can end an introductory offer (Taylor 2003) or simply raise their standard price once they have an established customer base. A large theoretical literature (see Farrell and Klemperer 2007 for a review) predicts this invest-then-harvest pricing pattern in a variety of contexts, ${ }^{6}$ and this pricing pattern is prevalent in many markets.

I examine the equilibrium effect of dynamic defaults in an invest-then-harvest model with overlapping generations of consumers. I consider both a perfectly competitive environment (e.g. electricity) and a monopoly seller (e.g. subscriptions to a magazine). In the competitive equilibrium, the choice of default affects efficiency but not the division of surplus between consumers and firms, as firms make zero profits. The monopolist model highlights strategic considerations in setting the initial price shows how the choice of default affects profits: unless consumers dislike automatic renewal enough to substantially reduce the number of consumers who enter the market, the monopolist will make higher profits under automatic renewal. As a corollary, if individuals are sufficiently myopic, the monopolist will always prefer the automatic renewal default.

Defaults affect the price elasticity of demand and thus the price differential between prices faced by new and repeat customers (i.e. introductory prices v. legacy prices, or the price of new entrants v. existing products.) Non-renewal defaults, such as automatic switching, can raise the elasticity of demand of existing consumers and thereby lower this equilibrium price differential; in a competitive market, this reduction comes from both higher initial prices and lower legacy prices. A lower equilibrium price differential can increase social welfare, as consumers not directly affected by the default switch less, reducing resources expended on adjustment costs. (There is also a reduction in the transfer of resources away from consumers who do not switch products, which may increase social welfare in the presence of distributional concerns for inattentive consumers.) Against these gains are weighed the increased adjustment costs borne by consumers directly affected by the default. I derive conditions under which an automatic switching default is privately and socially optimal.

When firms respond to incentives created by defaults, defaults have externalities, and the socially optimal default for the population may not coincide with the privately optimal

\footnotetext{
${ }^{6}$ More pejoratively, "bargains-then-ripoffs".
} 
default for an individual. For instance, automatic switching may be the socially optimal default because it lowers the equilibrium price differential between new and existing products. Yet a given individual may prefer that an automatic renewal default applied to him or her alone, allowing the individual to avoid bearing adjustment costs and leaving others to discipline the market. Thus, having consumers choose their own defaults will not necessarily lead to the socially optimal default being chosen.

This paper builds on the previous literature on defaults. Carroll et al. (2009) examine a different type of default - optimal initial assignment defaults for retirement savings - in a context where firms are not strategic actors. Their model assumes a particular source of inaction: individuals are quasi-hyperbolic discounters (Laibson 1997), and so do not opt-out of the default even if the gain is greater than the cost. As a result, individuals in Carroll et al. (2009) will certainly opt-out of the default if the consequences are bad enough, which motivates their results on active decisions and off-set defaults (defaults that would lead individuals to have poor outcomes if they did not act). In contrast, the model of switching frictions used in this paper can accommodate other psychological biases, such as forgetting or inattention. In this model, the probability an individual will act is increasing in the net gain to doing so, but allows for a positive probability that an individual will not act even if the gain to action is very high. Bernheim, Fradkin, and Popov (2011) also examine retirement savings rate defaults. They use the framework of Bernheim and Rangel (2009) to analyze the welfare effects of initial assignment defaults without taking a stance on the source of inertia. In contrast, for setting dynamic defaults, I show how choice data can be used to distinguish real adjustment costs from psychological factors leading to inaction, and conduct standard welfare analysis.

The paper is also related to the design of contracts in the presence of consumer biases, which find a variety of motivations for back-loaded fees. DellaVigna and Malmendier (2004) examine contract design when individuals are potentially are quasi-hyperbolic discounters. They find that firms introduce switching costs and charge back-loaded fees (e.g. making it difficult to cancel a gym membership) when individuals are time-inconsistent and naive about their inconsistency. In contrast, the price increases in the invest-then-harvest equilibrium result from the lack of long-term commitment and arise even with sophisticated consumers who correctly predict future behavior. This paper also examines the externalities defaults have on other consumers, and hence how defaults can be set to maximize social welfare. In other work, Gabaix and Laibson (2006) and Heidhues, Koszegi, and Murooka (2012) examine shrouded prices, in which all consumers see a base price and myopic consumers do not see the add-on price. Insights from the shrouded price models can applied to investthen-harvest models with a slight reinterpretation (myopic consumers may not anticipate 
the high legacy price). However, this present paper assumes (at least as a baseline) that consumers are sophisticated; it adds new analysis of dynamic defaults and how they interact with adjustment costs and psychological factors that lead to inaction.

This paper is organized as follows. Section 2 develops a model of consumers who have both classical adjustment costs and psychological factors that lead to inaction. Section 3 examines optimal dynamic defaults in competitive equilibrium and Section 4 examines the dynamic defaults in a monopoly market. Finally, Sections 5 and 6 discuss the implications of the results and conclude.

\section{Model of Consumer Behavior}

\subsection{Context}

In the model, let there be overlapping generations of consumers who live for two periods each ("young" and "old"), with a continuum of new consumers, normalized to measure one, arriving each period. Consumers have a constant per-period valuation $v_{i}$ for one unit of a non-storable product (and 0 for each additional unit). Consumers maximize their discounted expected utility, rationally anticipate their own future behavior and future firm behavior, and have linear utility for money in the region of the prices they face. Consumers discount future utility by $\delta<1$ each period.

Contracts are for one period each, which can be thought of as a standard contract term (e.g. a monthly rate for many internet service providers, a year for most health insurance products, 2-3 years for many cell phone products). Firms cannot commit to prices in future periods and consumers cannot commit to purchasing in future periods; incomplete contracts without commitment to future prices and purchases are commonly observed. Inability to commit can result from a number of factors, including regulatory constraints on the form of the contract (e.g. many insurance markets), or costs of writing and enforcing a sufficiently detailed commitment contract (i.e. on both cost and quality) given future uncertainty. ${ }^{7}$

\subsection{Consumer Behavior}

Consumers who purchased a product last period have three options: renew the purchase of the current product, switch to an alternative product, or cease purchasing all together. Consumers can either actively express their preference for one of these options, or they can do nothing and take the default. Actively expressing their preference requires "opt-out costs"

\footnotetext{
${ }^{7}$ When the model is generalized to allow firms to costlessly commit to future prices, contracts without commitment to future prices emerge endogenously if consumers are myopic about future firm behavior. Myopic consumers are unwilling to pay higher prices in the present for future gains.
} 


\section{Consumer's First Period ("Young")}

- Consumer knows distribution of $\omega$ and $\lambda$

- Consumer chooses product, giving utility $v_{i}-p_{\text {initial }}$ from purchase

\section{Consumer's Second Period ("Old")}

- Values of $\omega_{i}, \lambda_{i}$ are drawn from distribution

- Utility if consumer:

- switches: $v_{i}-p_{\text {initial }}-w$

- renews purchase: $v_{i}-p_{\text {legacy }}$

- does not purchase: $-\omega_{i}$

- Additional cost $\mathrm{\kappa}$ borne if actively opt-out of applicable default

- Consumer takes default unless gain to making active decision exceeds $\lambda_{i}$

Figure 1: Timeline

given by $\kappa$ (e.g. the cost of sending in a form), but taking the default is costless. In this section, I describe how $\kappa$ affects consumer behavior. However, since $\kappa$ is typically small, I assume $\kappa=0$ in Sections 3 and 4 of the paper for clarity of exposition and treat $\kappa>0$ in the Appendix.

There are two classes of frictions that affect behavior. Both sources of frictions will lead to inertial behavior when the default is automatic renewal, but will lead to different behavior under an automatic switching default. They can thus be distinguished using revealed preference (see Section 2.4.)

1. Consumers face real adjustment (or switching) costs that result from moving between products and that reduce welfare; these will lead consumers to prefer to stay with their current product, all else equal. Real adjustment costs are present in many markets: whether switched by active decision or by default, virtually every switch involves paperwork. When switching insurance plans, consumers need to learn the rules of their new plan; when switching checking accounts or credit cards, they may need to reenter billing and direct deposit information. Also counted under real adjustment costs is the experience of disutility from negative emotions (e.g. confusion, fear, loss aversion) that may occur when consumers switch. 


\section{Consumers are subject to psychological factors that lead to inaction (PFLIs).}

PFLIs affect whether a consumer actively expresses their preference, but not their welfare conditional on the action taken. PFLIs lead consumers to take the default; even when a consumer perceives a net benefit from acting, they may not make an active decision, but instead do nothing and take the default. For instance, an individual may wish to switch to another product but forget (Ericson 2011; Letzler and Tasoff 2012), procrastinate on taking action (O'Donoghue and Rabin 2001; Ariely and Wertenbroch 2002), or simply not be paying attention to this decision (Lacetera, Pope, and Sydnor 2010; Taubinsky 2013). Under an automatic renewal default, these inactivity factors lead consumers not to switch and simply take the default option, even though their welfare would be increased (as they themselves would judge it) if they were automatically switched to a cheaper product.

I capture adjustment costs by having each consumer pay $\omega_{i}$ if and only if they leave their current product. This cost $\omega$ is drawn from c.d.f. $G(\omega)$ in the consumer's second period; in the consumer's first period, the distribution $G$ is known but $\omega_{i}$ is unknown. Consumers bear the cost $\omega$ regardless of whether the switching results from their choice, or from them being switched by default. For instance, regardless of how consumers are switched between health insurance plans, they must set up new billing information and switch doctors if their previous doctor is not covered in the new plan's network.

I capture PFLIs by letting each consumer have a tolerance for inaction $\lambda_{i}$ : the consumer has a maximum tolerable loss from taking the default $\lambda_{i}$. This has the property that the probability a psychological factor will lead a consumer to take the default is decreasing in the gain to making an active decision. For instance, a consumer is more likely to pay attention and remember to switch credit cards the larger is the difference in interest rate between the two cards. The timing of the realization of $\lambda$ is the same as for $\omega: \lambda_{i}$ is drawn in the second period from the c.d.f $H(\lambda)$, independent of the distribution of $\omega$;in the consumer's first period, distribution $H$ is known but not the value of $\lambda_{i}$.

Although most of the existing optimal default literature has assumed individuals have quasi-hyperbolic ( $\beta-\delta$, Laibson 1997) preferences, quasi-hyperbolic preferences cannot plausibly explain default taking when the losses from inaction are extremely large (e.g. as in Handel [2013], see also discussions in Ericson [2011], Bernheim Fradkin, and Popov [2011]). Also, note that the distribution of $\lambda$ captures the fact that inaction is stochastic- consumers may not know whether they will forget to send in a form. PFLIs provide a more flexible framework to capture when individuals will take the default, as default-taking is likely the product of a complex interaction of many biases (e.g. memory and time-inconsistency interact in complex ways, as shown in Ericson [2014b]). In the next section, I show how PFLIs 


\section{All Defaults, Consumers without PFLIs $(\lambda=0)$}

\section{- Renew purchase if $\omega_{i}>\Delta p$}

\section{Automatic Renewal Default, Consumers with PFLIs $(\lambda>0)$}

- Take default and renew purchase if max. tolerable loss $\lambda_{\mathrm{i}}>\Delta p-\omega_{\mathrm{i}}$

\section{Automatic Switching Default, Consumers with PFLIs $(\lambda>0)$}

- Opt-out of default and renew purchase if $\lambda_{\mathrm{i}}<\omega_{\mathrm{i}}-\Delta \mathrm{p}$

Figure 2: Consumer Repeat Demand Under Different Defaults. Assumes products are perfect substitutes and opt-out $\operatorname{cost} \kappa=0$.

differ from quasi-hyperbolic preferences.

For simplicity in the paper's text, I assume that $\lambda$ is distributed such that $\lambda=\bar{\lambda}>0$ with probability $\psi$ and $\lambda=0$ with probability $1-\psi$. I refer to consumers with $\lambda=0$ as "attentive" and consumers with $\lambda=\bar{\lambda}$ as "inattentive", though $\lambda$ may result from many different biases. This two point distribution of $\lambda$ is only for ease of exposition; the Appendix shows the general case where $\lambda$ is drawn from a general $H(\lambda)$.

\subsection{Consumer Behavior Under Defaults}

I consider three potential default options ${ }^{8}$ that determine what happens if the consumer does not actively express their preference:

- Automatic renewal with the consumer's current product from the same firm.

- Automatic switching to the lowest priced product of the type the consumer chose.

- Non-purchase so that the customer buys no product.

${ }^{8}$ The default could, in principle, entail arbitrary consequences, such as a fine for non-responding. I assume that fines for not actively expressing preference are not feasible policies, due to concerns over the limit of government power and/or constraints on the ability to collect such fines. 
Consumer behavior depends on the default, their adjustment cost $\omega$, and their PFLI $\lambda$. Consider a consumer who purchased a product last period that is now priced at $p_{\text {legacy }}$. Switching to the cheapest identical product priced at $p_{\text {initial }}$ gives a utility gain of $\Delta U=$ $\Delta p=p_{\text {legacy }}-p_{\text {initial }}$. From this gain is subtracted the consumer's real adjustment cost $\omega_{i}$. Thus, whenever $\Delta p-\omega_{i t}>0$, a consumer would prefer to be switched to the cheaper product. However, their behavior is affected by costs of expressing preference $\kappa$, PFLIs $\lambda$, and the default.

Under the automatic renewal default, a consumer will actively choose to switch products if the net gain to switching exceeds their tolerance for inaction $\lambda_{i t}$, and otherwise take the default and stay in their current product. In order to switch, consumers must also actively express their preference and pay $\kappa$. Hence, a consumer switches under automatic renewal if $\Delta p-\omega_{i}-\kappa>\lambda_{i}$. With this default, a consumer is never switched when they prefer not to be switched $\left(\Delta p-\omega_{i}<0\right)$, but they sometimes do not switch even when there would be a gain to doing so.

Under the automatic switching default, a consumer must actively express their preference to stay in the current product. The gain to switching then comprises $\Delta p$ and the saved opt-out costs $\kappa$. Hence, a consumer switches under the automatic switching default if $\Delta p-\omega_{i}+\kappa>-\lambda_{i}$, tolerating a loss up to $\lambda_{i}$ from staying with the default and switching; that is, they will sometimes switch even if the adjustment cost from switching outweighs the financial gain. ${ }^{9}$

Under a non-purchase default, consumers get utility $v_{i}-p_{\text {legacy }}-\kappa$ from their current product if they actively express a preference to keep purchasing their current product, get $v_{i}-p_{\text {initial }}-\omega_{i}-\kappa$ if they actively express a preference to switch to a cheaper product, and $-\omega_{i}$ if they take the default. ${ }^{10}$ They opt-out of the default and choose their preferred option whenever $v_{i}-\kappa+\max \left\{-p_{\text {legacy }}+\omega,-p_{\text {initial }}\right\}>\lambda_{i}$.

Figure 2 summarizes consumer behavior, distinguishing between consumers who face no PFLIs ("attentive") and consumers who do ("inattentive" or "forgetful" consumers). Repeat

\footnotetext{
${ }^{9}$ In contrast, consider how an individual with quasi-hyperbolic preferences would behave before the deadline for responding. Set $\delta=1$ and $\lambda=0$. Then, under an automatic renewal default, the consumer would choose to switch whenever $\beta \Delta p>\omega+\kappa$, assuming $\kappa$ and $\omega$ are paid today. Under automatic switching, the only difference is that $\kappa$ needs to be paid in order to not switch, rather than to switch. Then, the consumer would choose to switch whenever $\beta \Delta p>\omega-\kappa$. The difference in the probability of switching is the probability that $\omega \in \beta \Delta p \pm \kappa$, which is limited for $\kappa$ small. However, PFLIs capture the fact that defaults can lead to large losses as $\lambda$ may be large with some probability (i.e. forgetting to send back an important form).

${ }^{10}$ Here, the adjustment cost $\omega$ is assumed to be the same if they move to a different product or no product at all. This could be generalized to allow adjustment costs and PFLIs to differ between non-purchase of a product and switching among products. For instance, having the electricity go out is a potent reminder to act and repurchase in electricity; foregone monetary gains from not switching to a cheaper supplier are not nearly so salient.
} 
demand for a product depends on the default; I use $D_{\text {repeat }}$ as the general term for the probability a consumer will repurchase the product, and indicate repeat demand under a particular default with a superscript: under automatic switching $D_{\text {repeat }}^{\text {Sw }}=\int_{0}^{\infty} H(\omega-\Delta p-\kappa) d G(\omega)$, and under automatic renewal $D_{\text {repeat }}^{\text {Re }}=1-\int_{0}^{\infty} H(\Delta p-\omega-\kappa) d G(\omega)$; repeat demand for a non-purchase default is discussed in Section 4.

\subsection{Identification of Real Adjustment Costs versus PFLIs}

This section shows how to separately identify real adjustment costs from PFLIs using a series of choice experiments. The key intuition is that while $\omega$ and $\lambda$ lead to similar behavior under an automatic renewal default, they lead to very different behavior under an automatic switching default.

Consider product $\mathrm{A}$ and product $\mathrm{B}$, and let $\mathrm{B}$ be the more preferred product. When products are not identical, the difference in their valuations for the product can be ascertained by eliciting willingness-to-pay (WTP) from new choosers (unattached to any product) ${ }^{11}$ for each product for one period only. For now, though, let product A and product B be perfect substitutes, so that the difference in utility from purchasing the products is just the price difference $\Delta p$.

The real adjustment cost $\omega$ can be identified by WTP to avoid being forced to switch between products next period. Consider a consumer who previously purchased product A, and who is now given a choice between staying in product A for certain versus being switched to product $B$ for certain next period. This identifies the expected value of $\omega$, as the difference in WTP is $\Delta p-E \omega$. If instead, this WTP is elicited immediately before the switching occurs, when $\omega_{i}$ is revealed to consumers, the ex-post distribution of $\omega$ can be identified, as it gives $\Delta p-\omega_{i}$. All these WTP elicitations hold $\kappa$ constant regardless of what the consumer chooses, since an active choice is required only at the time of elicitation.

To identify the costs $\kappa$ of opting-out of the default and expressing preference (e.g. sending in a form), the researcher can elicit WTP to avoid a task similar to the method of opting out. Moreover, $\kappa$ can also be identified from choice behavior in the market environment without needing to define a similar task. Consider a consumer who previously purchased product A, and elicit that consumer's WTP to be given a switching default versus an automatic renewal default. Appendix A.2 shows that this WTP is a function of $\kappa$ and other observable objects: the probability of switching times the gain to switching (observed in the data), the difference in adjustment costs borne under each default (elicited as above), and the probability of opting out of the default (observed in the data) times $\kappa$.

\footnotetext{
${ }^{11} \mathrm{WTP}$ could be elicited in a variety of incentive compatible ways, including the Becker-DeGroot-Marshack (1964) mechanism or the multiple price-list mechanism.
} 
PFLIs $\lambda$ can be measured in a few different ways. First, note that Proposition 2 will show that WTP for a given default regime will depend on $\lambda$. Another marker that PFLIs are affecting choice is if the difference in probability of switching under the automatic renewal versus automatic switching defaults is "too high". In the absence of PFLIs $(\lambda=0)$, consumers switch if $\omega<\Delta p \pm \kappa$ (depending on the default), and so the difference in switching is the probability that $\omega$ is between $\Delta p-\kappa$ and $\Delta p+\kappa$. For $\kappa$ small, the probability should be low; PFLIs allow for a larger effect of the default, as the difference in probabilities of switching is given by $\int_{0}^{\infty} \operatorname{Pr}(\omega \in[\Delta p \pm(\lambda+\kappa)] d H(\lambda)$.

The complete distribution $H(\lambda)$ can be traced out by experiments that compare behavior under different defaults. First, observe old consumers' choices under an automatic renewal regime (either to take the default and renew, or to opt-out and switch). Then, identify $\omega_{i}$ by (unexpectedly) eliciting consumers' WTP to switch. A consumer's choice to stay with the default can be compared to the estimated utility of doing so. Under a automatic renewal default, a consumer will only have opted-out and switched if $\Delta p-\omega_{i}-\kappa>\lambda$. Hence, the probability a consumer with $\omega_{i}$ did not opt out of the renewal default is $\operatorname{Pr}\left(\lambda>\Delta p-\omega_{i}-\kappa\right)$. By observing this probability for various values of $\omega_{i}$ and $\Delta p$, it is then possible to trace out $H(\lambda)$. Similar experiments can be done under an automatic switching default. ${ }^{12}$

\section{Dynamic Defaults and Competitive Equilibrium}

\subsection{Market Setup}

In order to analyze optimal defaults, we need to determine the equilibrium that results under each default. In this section, I describe competitive equilibrium with overlapping generations of consumers and then show conditions for optimal defaults. I assume there are $N \geq 2$ firms in the market. Firms can set prices separately for new purchasers (initial or introductory prices) and repeat purchasers (legacy prices). Because products are ex-ante identical and firms cannot commit to future behavior, consumers always choose the cheapest product when they enter the market. I assume all firms charging the same price receive an equal share of all the unattached consumers and switchers who choose a product with that price. For the competitive equilibrium, I assume valuation $v_{i}$ is high enough that a nonpurchase default is neither optimal nor credible (e.g. products that individuals are mandated to have, such as health or auto insurance, or are almost certain to have, such as electricity), and thus restrict discussion to automatic renewal or automatic switching defaults. ${ }^{13}$ Section

\footnotetext{
${ }^{12}$ In the model, I have assumed that the distribution of $\lambda$ is the same, regardless of which default applies. However, this same method can be used to identify the distribution of $\lambda$ separately under each default.

${ }^{13} \mathrm{~A}$ full treatment of non-renewal versus automatic switching defaults needs to specify how adjustment costs and PFLIs differ between non-purchase of a product and switching among products. For instance,
} 
4 discusses the effect of non-purchase defaults in the context of monopoly.

\subsection{The Invest-then-Harvest Equilibrium}

In setting prices, firms have two motives: an investment motive, to acquire market share for the future, and a harvesting motive, to maximize profits this period on new and existing customers. These incentives lead to an "invest-then-harvest" pricing pattern (Farrell and Klemperer 2007): low initial prices (perhaps below marginal cost), and higher "legacy" prices for repeat purchasers.

Each firm offers one product and sets its price for first-time purchasers $p_{\text {initial }}$ and legacy price $p_{\text {legacy }}$ each period, competing via Bertrand competition on prices only. The cost of each customer to the firm is a constant $c$. Firms are infinitely lived with discount factor $\delta$, and seek to maximize the expected discounted present value of profits $V_{t}$, which is given by flow profits and future profits in the recursive equation:

$$
V_{t}=\left(p_{t, \text { initial }}-c\right) D_{t, \text { new }}+\left(p_{t, \text { legacy }}-c\right) D_{t, \text { repeat }}+\delta V_{t+1}\left(D_{t, \text { new }}\right)
$$

where $D_{t, \text { repeat }}$ is repeat demand from consumers who bought from the firm in period $t-1$, and $D_{t, n e w}$ is the demand of potential switchers from other products and new customers entering the market unattached to any product. The last term captures that future firm value depends on its current market share. The firm's first order condition for optimal legacy pricing is thus $p_{\text {legacy }}=c+\frac{1}{\eta_{\text {repeat }}}$, where $\eta_{\text {repeat }}=\frac{-D_{\text {repeat }}^{\prime}}{D_{\text {repeat }}}$ is the negative of the semi-elasticity of repeat consumers. Note that repeat demand, its semi-elasticity, and $V$ all depend on the choice of default. In a perfectly competitive environment, the zero-profit condition determines $p_{\text {initial }}$. Under imperfect competition, the firm's first order condition for the introductory price gives $p_{\text {initial }}=c+\frac{1}{\eta_{\text {new }}}+\delta V_{t+1}^{\prime}\left(D_{\text {new }}\right)$, where $\eta_{\text {new }}=\frac{-D_{\text {new }}^{\prime}}{D_{\text {new }}}$. Because potential repeat customers face adjustment costs, they are likely to have relatively inelastic demand compared to new customers entering the market, who can choose from many close substitutes.

Proposition 1. For a given default, a competitive equilibrium exists and takes the following form: each period, firms set introductory prices $p_{\text {initial }}^{*}=c-\frac{\delta}{\eta_{\text {Repeat }}} \frac{D_{\text {repeat }}}{1+\left(1-D_{\text {repeat }}\right)}$ and legacy prices $p_{\text {legacy }}^{*}=c+\frac{1}{\eta_{\text {repeat }}}$. All young consumers purchase a product at an introductory price. Fraction $1-D_{\text {repeat }}$ of old consumers switch to a different product and get an introductory price.

having the electricity go out is a potent reminder to act and repurchase in electricity; foregone monetary gains from not switching to a cheaper supplier are not nearly so salient. 
The intuition behind the results can be simply seen by examining how consumers and firms would behave if the market were ending this period. This is equivalent to setting $\delta=0$. Young consumers and old switchers simply choose the cheapest product, as they are all perfect substitutes. Hence, when firms set prices for new customers, they face a perfectly elastic demand curve, and set price equal to marginal cost: $p_{\text {initial }}=c$. For repeat customers, firms have market power over repeat customers due to adjustment costs and PFLIs. Given that consumers who switch products will switch to a product sold at price $p_{\text {initial }}$, firms simply set legacy prices with their first-order condition. (In contrast, when there are neither adjustment costs nor PFLIs, introductory and legacy prices are both set to marginal cost, as consumers would simply choose the cheapest product each period.)

With $\delta>0$, the firm's first order condition and the elasticity of repeat demand still determines $p_{\text {legacy }}$. Bertrand competition implies that the market is perfectly competitive for introductory prices, and so firms compete away the profits they will later make on consumers "stuck in place". The zero-profit condition implies $p_{\text {initial }}=c-\delta\left(p_{\text {legacy }}-c\right) \frac{D_{\text {repeat }}}{1+\left(1-D_{\text {repeat }}\right)}$. The last fraction arises because firms only sell at the higher legacy price to (old) repeat customers, but sell at introductory prices to both old and young first-time customers. ${ }^{14}$ This then simplifies to $p_{\text {initial }}=c-\frac{\delta}{\eta_{\text {Repeat }}} \frac{D_{\text {repeat }}}{1+\left(1-D_{\text {repeat }}\right)}$. Initial prices are now lower than marginal cost, as firms invest in acquiring market share in the future. Define $\Delta p \equiv p_{\text {legacy }}-p_{\text {initial }}$ as the price differential between legacy and initial prices.

Compared to a situation in which firms could commit to future prices or simply charged the same price each period, this equilibrium is inefficient. So long as consumers bear some real adjustment costs, switching between identical products is a waste. These results also suggest other potential inefficiencies. Because switching is higher, firms and consumers may have reduced incentives to invest in relationship-specific investments (e.g. insurer investments in enrollees' future health). ${ }^{15}$

\subsection{Privately Optimal Defaults}

Given this equilibrium, I first consider what defaults are privately optimal: what default an individual consumer would choose for themselves, holding fixed the defaults that everyone

\footnotetext{
${ }^{14}$ By assumption, firms can price on purchase history but not age. If firms could price on both age and purchase history, competition would set prices equal to marginal cost $c$ for old switchers. Legacy prices for repeat purchasers would be set based on the elasticity of repeat demand, and introductory prices for young consumers would simply be equal to $c-\delta\left(p_{\text {legacy }}-c\right) D_{\text {repeat }}$.

${ }^{15}$ Proposition 1 describes an equilibrium in which competition implies that firms do not make excess profits as a result of inertia, even if consumers are myopic. For models of imperfect competition, there is an active debate about whether switching costs raise or lower the average level of markups: compare Farrell and Klemperer (2007) and Dubé, Hitsch \& Rossi (2009), who find that the effect of switching costs on average markups are non-monotonic and depend on the setting.
} 
else faces. In this analysis, the prices a consumer faces do not vary depending on the default they choose. It is commonly found that consumers can change their default renewal option at some point during the contract without changing their price; in many markets, regulators do not allow prices to vary depending on the default (insurance exchanges, utilities, cable/internet). ${ }^{16}$ Moreover, consumers can implement their chosen default with third-party services (unobserved by the firm): an insurance broker could be instructed to switch or renew policies, a personal finance website such as mint.com could be given permission to automatically cancel old credit cards and apply for new ones when better deals are available, and in general, automation scripts can automatically cancel orders or place new ones (see the consumer site "if-this-then-that" at ifttt.com).

While the equilibrium that obtains under a given default regime depends only the switching behavior of consumers, the optimal default will depend on the relative contributions of adjustment costs versus PFLIs. Because choice of default depends on the source of frictions, this analysis again shows how adjustment costs can be distinguished from PFLIs via revealed preference. When choosing a default for herself, a consumer weighs the change in prices paid against the change in adjustment costs borne, taking into account that PFLIs will affect their behavior. (Recall, that for exposition I assume consumers are inattentive or forgetful with probability $\psi$, in which case $\lambda=\bar{\lambda}$, and are otherwise attentive with $\lambda=0$. $)^{17}$

Proposition 2 below considers when automatic switching versus automatic renewal would be the optimal default for an individual consumer or small group (formally, the case where the default affects a measure-zero subset of the population.)

Proposition 2. Under perfect competition, the privately optimal dynamic default is automatic switching if $\int_{0}^{\bar{\lambda}+\Delta p} \omega d G(\omega)<\Delta p \cdot G(\bar{\lambda}+\Delta p)$, and is otherwise automatic renewal.

The intuition behind Proposition 2 is as follows: the default only matters for consumers when they are inattentive or forgetful. Consumers compare the expected additional adjustment costs borne under automatic switching to the amount of price savings. Under automatic switching, inattentive consumers switch whenever the adjustment cost is below the threshold $\bar{\lambda}+\Delta p$, which occurs with probability $G(\bar{\lambda}+\Delta p)$. They save $\Delta p$ when they switch, but expected adjustment costs are the integral of $\omega$ up to that threshold. A consumer's willingness to pay for an automatic renewal default over an automatic switching default

\footnotetext{
${ }^{16}$ If consumers were instead to choose among products with default-specific prices, they would also consider the effect of the differential prices paid and how that affected switching behavior when attentive as well.

${ }^{17}$ I set opt-out costs $\kappa=0$ here, but treat positive $\kappa$ in Appendix Section A.2. The results are similar, with $\kappa>0$ creating an additional motivation to choose a default that matches the modal switching behavior of the population: if most people switch plans each period, then an automatic switching default might raise welfare by saving most people the cost of opting out of the default.
} 
is $\psi\left[\Delta p \cdot G(\bar{\lambda}+\Delta p)-\int_{0}^{\bar{\lambda}+\Delta p} \omega d G(\omega)\right]$, where $\psi$ captures the probability the consumer draws a PFLI.

If the price differential is small but $\bar{\lambda}$ is high, then automatic switching will not typically be optimal, since inattentive consumers would bear large adjustment costs (up to $\bar{\lambda}$ ) for little gain. Conversely, when $\Delta p$ is large because consumers are inattentive, but consumers do not face many real adjustment costs, automatic switching will be optimal. The privately optimal default can be determined by eliciting (from sophisticated consumers) their willingness to pay to move from one default to another, or from the distributions of $\lambda$ and $\omega$ as elicited in Section 2.4.

\subsection{Socially Optimal Defaults}

Defaults have externalities, and so the socially optimal default for consumers may differ from the privately optimal default. I assume the social welfare function attaches equal welfare weights to all consumers; given the zero-profit condition, payments to firms are simply transfers from one consumer to another. Thus, the socially optimal default minimizes total adjustment costs borne.

When defaults are chosen for the entire population of consumers, the response of firms to the default must be considered. Moving from an automatic renewal default to an automatic switching default alters the elasticity of demand of existing consumers, and so the equilibrium price differential $\Delta p$ between introductory and legacy prices will differ under the two defaults. Let this differential take the value $\Delta p_{S w}$ under an automatic switching default and $\Delta p_{R e}$ under an automatic renewal default. Proposition 3 shows that whether automatic switching or automatic renewal is optimal will depend on the difference between $\Delta p_{S w}$ and $\Delta p_{R e}$.

Proposition 3. Under perfect competition, the socially optimal dynamic default for the population is automatic switching if $\psi \int_{0}^{\bar{\lambda}+\Delta p_{S w}} \omega d G(\omega)<(1-\psi) \int_{\Delta p_{S w}}^{\Delta p_{R e}} \omega d G(\omega)$, and is otherwise automatic renewal.

Proposition 3 shows that the socially optimal default compares the two effects of automatic switching. First, automatic switching increases the probability the $\psi$ inattentive consumers will switch, increasing their adjustment costs borne. This increases the elasticity of demand firms face ${ }^{18}$ and so lowers the equilibrium price differential between introductory and legacy prices: $\Delta p_{S w}<\Delta p_{R e}$. As a result, we have our second effect: the $1-\psi$ attentive consumers are less likely to switch under an automatic switching default. Social welfare counts as a gain the reduction in adjustment costs borne by attentive consumers who draw

\footnotetext{
${ }^{18}$ In this simple setting in which $\lambda_{i t}$ is either 0 or $\bar{\lambda}$, it is always the case that $\Delta p_{S w}<\Delta p_{R e}$. However, for some distributions of $\lambda, \Delta p_{S w}>\Delta p_{R e}$ due to more inelastic demand.
} 
$\omega$ in the region between $\Delta p_{S w}$ and $\Delta p_{R e}$ and do not switch. Automatic renewal may be optimal if inattentive consumers bear large adjustment costs but automatic switching has only a small effect on prices. Conversely, automatic switching is optimal if inattentive consumers drive firms' prices but do not bear large adjustment costs.

Defaults have externalities, as illustrated by the difference between the optimal default from a given individual consumer's perspective and the optimal default for the entire population. In some cases, automatic switching may be the optimal population default because it raises the elasticity of demand and leads to lower price differentials; nonetheless, a given consumer may prefer that his or her own default was automatic renewal to save his or her own adjustment costs, leaving other people to discipline the market. The other case is possible as well. When automatic switching does not change $\Delta p$ very much, automatic renewal will typically be socially optimal since there will be little savings in adjustment costs by attentive individuals (the term $(1-\psi) \int_{\Delta p_{S w}}^{\Delta p_{R e}} \omega d G(\omega)$ will be small). However, faced with $\Delta p_{R e}$, a given consumer may prefer that he or she (alone) faced an automatic switching default that leads to price savings when he or she is inattentive: $\int_{0}^{\bar{\lambda}+\Delta p_{R e}} \omega d G(\omega)<\Delta p_{R e} \cdot G\left(\bar{\lambda}+\Delta p_{R e}\right)$.

The socially optimal default can be determined if the distributions of $\lambda, \omega$ are elicited as in Section 2.4. However, there are simpler ways of identifying these terms. The increased adjustment costs borne by inattentive consumers $\psi \int_{0}^{\bar{\lambda}+\Delta p} \omega d G(\omega)$ can be identified from WTP for an automatic switching default over an automatic renewal default; Proposition 2 showed that this is the difference between the sought after adjustment costs and the (observable) price savings from inattentive switching. The adjustment costs of attentive people $(1-\psi) \int_{0}^{\Delta p} \omega d G(\omega)$ can be identified by consumers' WTP to avoid being forced to stay in their current product next period for sure next period versus having a given default, which is comprised of price savings (observable), inattentive, and attentive adjustment costs. The WTP for an automatic switching default regime over certain staying in the current product is $\Delta p\left(q_{S w}\right)-\psi \int_{0}^{\Delta p+\bar{\lambda}} \omega d G(\omega)-(1-\psi) \int_{0}^{\Delta p} \omega d G(\omega)$, with the first two terms already identified. This WTP can be elicited for a market with $\Delta p=\Delta p_{R e}$ and $\Delta p=\Delta p_{S w}$, allowing us to identify $(1-\psi) \int_{\Delta p_{S w}}^{\Delta p_{R e}} \omega d G(\omega)$.

\subsection{Extension of Equilibrium Model}

Although the model presented above was a simple two-period consumer model, the form of equilibrium and optimal dynamic default conditions can be generalized to richer models. First, note that while I assumed that firms could distinguish between new and existing customers, this equilibrium can be generalized to the case where firms cannot set prices that differ between new customers and repeat customers, either because of legal restrictions or information limitations. In such a case, firms with no attached customer base (i.e. new firms, 
or firms whose customer base has left) set low prices $p_{\text {initial }}$ as in Proposition 1 to appeal to new consumers and switchers. Legacy firms (who offered the product in the previous period and who thus have a base of "attached" consumers) set prices equal to $p_{\text {legacy }}$ as in Proposition 1. ${ }^{19}$ Such an equilibrium has been observed in Medicare Part D by Ericson (2014a).

Appendix Section A.3 shows that the model can also be generalized to a market with infinitely-lived consumers with a constant hazard of dying each period: in such a model, set lower introductory prices and legacy prices, and (each period) consumers have an incentive to switch to competing firms to get lower introductory prices. Each period, they face adjustment costs and PFLIs. The resulting equilibrium and optimal defaults are similar to that in the two-period overlapping generations case.

\section{Defaults with a Monopolist Seller}

\subsection{Context}

Examining a context with a monopolist seller allows us to examine non-purchase defaults along with strategic considerations in the setting of the introductory price. In this analysis, consumers decide each period whether to purchase the product; there is no switching, as there is only one seller. A single firm sells the product, and consumer $i$ has per-period valuation $v_{i}$, with $v_{i}$ distributed with c.d.f. $W$ that is independent of the distributions $G, H$. As before, consumers live two periods (young and old), have discount factor $\delta$ (shared by the monopolist), know the distributions $G, H$ in advance but not their future draw from those distributions, and correctly forecast the second period behavior of firms and themselves. The monopolist knows the distribution $W$ but does not know any particular consumer's valuation. The monopolist can distinguish between repeat customers and new customers, and thus can set two prices: $p_{\text {legacy }}$ for repeat customers and $p_{\text {initial }}$ for new customers. I continue to assume $\kappa=0, \lambda=\bar{\lambda}>0$ with probability $\psi$ and $\lambda=0$ otherwise.

\subsection{Consumer Behavior and Monopolist Price Setting}

Here, we examine how consumers behave for a given default, and show how the monopolist will set prices for a given default. Consumers can choose whether to enter the market and buy when young and then whether they repurchase when old. ${ }^{20}$ Working backwards, consider

\footnotetext{
${ }^{19}$ The equilibrium is similar to that in Farrell and Shapiro (1988), who model a duopoly with overlapping generations and perfect substitutability between goods: they find an "alternating equilibrium" in which firms cycle between selling to new consumers only or selling to old consumers only.

${ }^{20} \mathrm{I}$ assume that consumers who do not purchase when young do not enter the market when old. This can be thought of as resulting from large adjustment costs that are incurred when moving from the outside
} 
the choice of whether to repurchase the product. Repurchasing yields utility $v_{i}-p_{\text {legacy }}$, while not purchasing entails bearing an adjustment cost, giving utility $-\omega_{i}$. Attentive consumers $(\lambda=0)$ will thus repurchase the product iff $\omega_{i}>p_{\text {legacy }}-v_{i}$, noting that even an attentive consumer may repurchase in cases where price exceeds valuation in order to avoid bearing the adjustment cost. Inattentive consumers $(\lambda=\bar{\lambda})$ face the same incentives, but have a wedge between their action and welfare. Under an automatic renewal default, an inattentive consumer will repurchase whenever their adjustment cost $\omega_{i}$ is greater than a threshold, that is whenever

$$
\omega_{i}>p_{\text {legacy }}-v_{i}-\bar{\lambda} \equiv \omega_{v_{i} R e}^{*}
$$

Note that the renewal threshold depends on the default and the consumer's valuation $v_{i}$. Under a non-purchase default, inattentive consumers are strictly less likely to repurchase: they do so whenever $\omega_{i}>\omega_{v_{i} N o n}^{*} \equiv p_{\text {legacy }}-v_{i}+\bar{\lambda}$. Under a generic default, I write the renewal threshold as $\omega_{v_{i} \text { Def }}^{*}$ and write repeat demand for a consumer with valuation $v$ as $D_{\text {old }}^{\text {Def }}(v)$.

Now, consider consumer behavior when young. The consumer will buy whenever $v_{i}-$ $p_{\text {initial }}+\delta E \hat{U}_{i}^{\text {Def }}>0$, where $E \hat{U}_{i}^{\text {Def }}$ is their expected utility when old, which will depend on both the default and legacy prices. Under a regularity condition ${ }^{21}$, there is a defaultspecific purchase threshold solution such that consumers purchase the product if and only if $v_{i} \geq v_{i}^{* D e f}$.

This allows us to derive the population demand of the young and old consumers: ${ }^{22}$

$$
\begin{aligned}
D_{\text {young }}^{\text {Def }} & =1-W\left(v_{\text {Def }}^{*}\right) \\
D_{\text {old }}^{\text {Def }} & =\int_{v_{\text {Def }}^{*}}^{\infty}\left[1-\psi G\left(\omega_{v_{i} \text { Def }}^{*}\right)-(1-\psi) G\left(p_{\text {legacy }}-v\right)\right] d W(v)
\end{aligned}
$$

The monopolist simply wants to maximize total discounted profits $\left(p_{\text {initial }}-c\right) D_{\text {young }}+$ $\delta\left(p_{\text {legacy }}-c\right) D_{\text {old }}$. The first-order condition for the legacy price gives $p_{\text {legacy }}^{*}=c+\frac{1}{\eta_{\text {old }}}$, with $\eta_{\text {old }}=\frac{-D_{\text {old }}^{\prime}}{D_{\text {old }}}$. Now, instead of a zero profit condition determining the introductory price, $p_{\text {initial }}$ is determined by invest-then-harvest incentives. Note that changing $p_{\text {initial }}$ not only

option entailed by non-purchase to purchasing the product. This portion of the model could be generalized at the cost of additional complexity (specifying another adjustment cost distribution). The choice of whether to delay entry to the market until old in order to avoid the legacy price is an artifact of the two period model; and would be less important in a multi-period model.

${ }^{21}$ The regularity condition is required because of the wedge $\lambda$ places between action and welfare, and requires that the lifetime utility of the product not be decreasing in $v$, or $1+\delta\left[1-D_{\text {old }}^{R e}(v)\right]-\delta \psi g\left(\omega_{R e, v, \bar{\lambda}}^{*} \lambda>\right.$ 0 , which is true for small $\psi$ and $g$. Note that there is always a threshold solution with a non-purchase default.

${ }^{22}$ Note that $D_{\text {new }}$ and $D_{\text {repeat }}$ from the competitive equilibrium case differ from the demand curves defined here, as first-time purchasers at the firm are all young in the monopoly model. 
affects demand of initial purchasers, but has an effect on repeat demand by changing the mix of who enters the market. The monopolist accounts for this effect: the first-order condition gives $p_{\text {initial }}^{*}=c+\frac{1}{\eta_{\text {young }}}-\frac{1}{\eta_{\text {old }}} \delta\left(\frac{d D_{\text {old }} / d p_{\text {initial }}}{d D_{\text {young }} / d p_{\text {initial }}}\right)$, where $d D_{\text {young }} / d p_{\text {initial }}$ and $d D_{\text {old }} / d p_{\text {initial }}$ capture how changes in the introductory price affect initial and repeat demand, respectively.

By affecting demand, the defaults will also affect monopolist profits. First, note that for any consumer with $v_{i}$ who entered the market, repeat demand at any given price is higher under automatic renewal than under the non-purchase default. Holding constant price, the increase in repeat demand under automatic renewal depends on the probability and degree of inattentiveness $(\psi$ and $\lambda)$, and is given by $\psi \operatorname{Pr}\left(\omega \in\left(p_{\text {legacy }}-v \pm \lambda\right)\right.$. As a result, holding fixed the population who enters the market, the monopolist makes higher profits on repeat customers under automatic renewal. A sufficient condition for the monopolist to prefer automatic renewal is that demand of young consumers is weakly higher under automatic renewal $\left(v_{N o n}^{*}>v_{R e}^{*}\right)$. In order for the automatic switching default to be preferred, demand of young consumers has to be lower enough under automatic renewal to offset the additional profits automatic renewal would give on repeat purchasers. (Also note that in the absence of the ability to commit to a default regime, the monopolist would always have an incentive to switch to automatic renewal defaults.)

\subsection{Optimal Defaults}

First, consider the privately optimal default (holding fixed the demand of the rest of the population- and thus, prices) for someone who purchases when young under both defaults. Then, the consumer prefers the non-purchase default to the automatic renewal default if the reduced probability of repurchase times the net utility of purchase outweighs the increase in adjustment costs borne.

Proposition 4. With a monopolist seller, the privately optimal dynamic default for a consumer who enters the market under both defaults is non-purchase iff

$$
\left(p_{\text {legacy }}-v\right)\left[G\left(p_{\text {legacy }}-v_{i}+\bar{\lambda}\right)-G\left(p_{\text {legacy }}-v_{i}-\bar{\lambda}\right)\right]>\int_{p_{\text {legacy }}-v_{i}-\bar{\lambda}}^{p_{\text {legacy }}-v_{i}+\bar{\lambda}} \omega d G(\omega)
$$

and is otherwise automatic renewal. If the consumer enters the market for only one default, their privately optimal dynamic default is the one under which they enter.

Proposition 4 shows that necessary condition for non-purchase to be privately optimal is that $v<p_{\text {legacy }}$ (the consumer does not want to buy at the second period price), since the left hand side of the inequality must outweigh the adjustment-costs avoided under automatic renewal and the difference in second period inattentive demand $G\left(p_{\text {legacy }}-v_{i}+\bar{\lambda}\right)-$ 
$G\left(p_{\text {legacy }}-v_{i}-\bar{\lambda}\right)$ is positive. Yet supposing that $v<p_{\text {legacy }}$, the intuition that a lower valuation makes automatic renewal more desirable is not true. Another way of writing Proposition 4's condition for non-purchase to be privately optimal is $p_{\text {legacy }}-v>E\left[\omega \mid \omega \in\left(p_{\text {legacy }}-v\right) \pm \bar{\lambda}\right]$, which depends crucially on the distribution of $\omega$ between the two renewal thresholds.

Now, consider the socially optimal default. Again, social welfare is comprised of consumers' valuation minus marginal cost of production minus any adjustment costs borne; prices matter only insofar as they affect behavior. The choice of default can affect social welfare through three channels: repeat demand from attentive consumers, repeat demand from inattentive consumers, and a change in the mix of consumers who enter the market. Below, I define the change in social welfare when moving from automatic renewal to a non-purchase default as $\Delta A t t$ for attentive consumers and $\Delta$ Inatt for inattentive consumers (so that the terms are positive if non-purchase gives higher social welfare). Thus, we have:

- Attentive consumers: The default affects $p_{\text {legacy }}$ by changing the elasticity of repeat demand. When the non-purchase default lowers $p_{\text {legacy }}$, more consumers who are attentive will repurchase when old, which increases social welfare since $p_{\text {legacy }}>c$. Holding fixed initial demand, the social gain to repurchase is $v_{i}-c+\omega_{i}$, while attentive consumers purchase if $v_{i}-p_{\text {legacy }}+\omega_{i}>0$. For each consumer type $v_{i}$, define $\Delta A t t\left(v_{i}\right)=(1-\psi) \int_{p_{\text {legacy }}^{N o}-v_{i}}^{p_{\text {legacy }}^{R e}-v_{i}}\left(v_{i}-c+\omega\right) d G(\omega)$ : the social surplus for this group under the non-purchase default minus that under automatic renewal, weighted by the probability of being attentive.

- Inattentive consumers: Holding fixed price, fewer inattentive consumers will renew under a non-purchase default. These cancellations are a loss when $v_{i}-c>\omega_{i}$, but are a gain for inattentive people who drew high adjustment costs. Moreover, the default also affects the mix of inattentive consumers who take the default by changing $p_{\text {legacy }}$ and thus the net gain to an active decision. For each consumer type $v_{i}$, define this term as $\Delta \operatorname{Inatt}\left(v_{i}\right)=-\psi\left[\int_{p_{\text {legacy }}^{R e}-v_{i}-\bar{\lambda}}^{p_{\text {Rogacy }}^{\text {Ro }}-v_{i}+\bar{\lambda}}\left(v_{i}-c+\omega\right) d G\right]$.

- Change in who enters the market: Defaults change consumers' expected utility when old, and thus change who purchases when young. So long as $p_{\text {initial }}>c$, the increase in initial purchases raises social welfare: consumers only purchase if their expected utility is positive, and social welfare is simply expected utility plus prices paid minus the costs of the product (when purchased). The expected two period social surplus from a consumer with valuation $v_{i}$ entering the market under a default Def is $\operatorname{New} w^{D e f}\left(v_{i}\right)=$ $\left(v_{i}-c\right)\left[1+\delta D_{\text {old }}^{D e f}\left(v_{i}\right)\right]-(1-\psi) \int_{0}^{p_{\text {legacy }}-v_{i}} \omega d G(\omega)-\psi \int_{0}^{\omega_{v_{i} D e f}^{*}} \omega d G(\omega)$.

Having defined these terms, we have the following proposition: 
Proposition 5. With a monopolist seller, the socially optimal dynamic default is nonpurchase iff $\delta \int_{\max \left\{v_{R e}^{*}, v_{N o}^{*}\right\}}^{\infty}[\Delta A t t(v)+\Delta \operatorname{Inatt}(v)] d W(v)>\int_{v_{R e}^{*}}^{v_{N o n}^{*}} N e w^{\text {Def }}(v) d W(v)$, where Def is the default under which more consumers enter the market when young, and is otherwise automatic renewal.

On the left-hand side of the inequality, we integrate the change in social welfare over all the consumers with valuations that entered the market under both defaults. Their behavior when young is unchanged, so this term is comprised of the change in behavior when old, is discounted by $\delta$, and is decomposed into terms for attentive and inattentive consumers. The right-hand side of the inequality integrates over the additional consumers who purchase only under one default. The threshold for purchase $v^{*}$ depends on the default; the default that brings the most consumers into the market will depend on the distributions of $F, G$, and $W$. If there are more initial purchasers under automatic renewal $\left(v_{N o n}^{*}>v_{R e}^{*}\right)$, the introductory price under automatic renewal is low enough to outweigh any potential benefit of the non-purchase default on the legacy price or unintended renewals.

\subsection{Extension: Myopia}

Up until now, we have assumed that consumers are sophisticated about their future behavior and firms' future behavior. However, consumers can be myopic in at least four different ways: they can disregard the future entirely (setting $\delta=0$ ), they can mistakenly believe that they will not have PFLIs (when young, perceived $\hat{\lambda}=0$ but actually $\lambda>0$ when old), they can mistakenly believe that they will not have adjustment costs (when young, perceived $\hat{\omega}=0$ but actually have $\omega>0$ when old), and they can mistakenly believe that introductory prices will persist (an anticipated legacy price that is equal to $p_{\text {initial }}$ ).

Myopic consumers enter the market too often. Consumers should only enter if $v_{i}-$ $p_{\text {initial }}+\delta E U(v)>0$, where $E U(v)$ is the consumer's expected utility when old. Note that $E U(v)$ is negative for $v_{i}=p_{\text {initial }}$, as legacy prices are higher than $p_{\text {initial }}$ and adjustment costs are (in expectation) positive; thus, this consumer should not enter the market. However, a consumer with $v_{i} \geq p_{\text {initial }}$ will enter the market if $\delta=0$ (they disregard the future), or if $\hat{p}_{\text {legacy }}=p_{\text {initial }}$ (they anticipate weakly positive next period utility), or if $\hat{\omega}=\hat{\lambda}=0$ (they anticipate not purchasing next period but without facing adjustment costs). Thus, all consumers who should enter the market do so (the optimal purchase threshold $v^{*}>p_{\text {initial }}$ ), along with additional consumers who should avoid the market.

From the monopolist perspective, then, myopia is quite attractive: not only does it enable the monopolist to set the preferred automatic renewal default (since initial demand is unaffected by the default when consumers are myopic), it also expands who enters the 
market (which surely increases profits if $p_{\text {initial }}>c$ ).

\section{Discussion}

Implementing an automatic switching default may require a market organizer with access to the menu of prices a consumer faces and regulatory authority to implement a switch. They are thus ideal for consideration in markets that are government-organized markets, such as health insurance exchanges. However, automatic switching defaults can also be implemented by private, third-party clearinghouses, such as a travel website that allows you to search many different airlines, brokers in an insurance market, or a consumer finance site that tracks products offered by many different banks. Non-purchase defaults can be implemented with less information or organization.

The model can be extended in several ways. I have assumed that firms cannot make long-term commitments to future prices, but do assume that firms can commit to the default that they apply. This state of affairs is often observed in markets, and it is likely that contracting on the default is simpler than writing a state-contingent contract for future

prices. Yet if firms were not able to commit to future defaults, and defaults were not set by a regulator, products with automatic switching default would be undersupplied. Suppose a consumer preferred an automatic switching default, even though it would lead to a higher initial price. Even if firms initially offered automatic switching defaults, the firm would have an incentive to change the default to automatic renewal in later periods in order to raise demand for its product. Not only would automatic switching defaults be only transitorily applied, but consumers (foreseeing future firm behavior) would be less likely to pay extra to choose automatic switching defaults.

More complex switching defaults could be considered. I have assumed that products are homogenous, but automatic switching could also apply in contexts with heterogenous products. A market designer implementing a switching default could use information to predict a consumer's next-best match (i.e. switching to the cheapest insurance plan that contained one's doctor and had the same deductible). The analysis of the optimal default in such a market could also take into account that automatic switching may disrupt the unobserved match quality between a consumer and a product. Other switching defaults could also depend on $\Delta p$ : the probability that a consumer is automatically switched could increase in $\Delta p$, or consumers could only be switched if $\Delta p$ exceeds some threshold. These defaults would then shape the demand curve for firms. However, if set by the regulator, they could begin to approximate price regulation. 


\section{Conclusion}

While dynamic defaults affect many markets, they have received little study. The investthen-harvest pricing pattern is prevalent, and leads to incentives for individuals to switch products. This paper provided a framework for determining how individuals choose dynamic defaults for themselves, trading off price savings versus adjustment costs and taking into account that they may face PFLIs. These dynamic defaults have externalities through firm pricing, so the decentralized choice of default will not necessarily lead to the socially optimal default. This paper provided conditions under which the various defaults would be optimal.

While this paper focused on the equilibrium effects of dynamic defaults, firms will also respond to other types of defaults. For instance, consider an employer administering a retirement savings plan that is choosing between requiring an active decision versus setting a default savings rate and fund allocation. If the retirement savings plan contains competing mutual funds, the choice of default rule may affect the price elasticity competing funds face when setting management fees. If active decision increases (decreases) competitive pressure on firms when setting fees, then the equilibrium level of fees will be lower (higher) under this policy than under a default assignment policy. While empirical work thus far has focused on showing default effects on individual behavior, future empirical work should also examine the equilibrium effects of changes in default rules.

The distinction between adjustment costs and PFLIs is relevant for contracting and competition in many contexts. Often, a failure to switch products under an automatic renewal default has been interpreted as evidence of adjustment costs. However, PFLIs can also lead to a failure to switch when an automatic renewal default applies. Adjustment costs and PFLIs have different welfare implications, lead to different choices of defaults, and can be distinguished using revealed preference. PFLIs provide a general framework for inactivity resulting from numerous psychological sources (e.g. procrastination, memory, and inattention) that can interact with each other in complex ways. This PFLI framework can be applied to the analysis of other types of defaults and can be useful for interpreting inertia observed in markets.

\section{REFERENCES}

Abadie, Alberto, and Sebastien Gay. 2006. "The Impact of Presumed Consent Legislation on Cadaveric Organ Donation: A Cross-Country Study." Journal of Health Economics 25 (4): 599-620. 
Ariely D, Wertenbroch K. 2002. "Procrastination, Deadlines, and Performance: SelfControl by Precommitment." Psychological Science, 13, 219-224.

Becker, G. M., M. H. DeGroot, and J. Marshak. 1964. Measuring Utility by a Single Response Sequential Method, Behavioral Science, 9, 226-232.

Bernheim, Douglas, Andrey Fradkin, and Igor Popov. 2011. "The Welfare Economics of Default Options: A Theoretical and Empirical Analysis of 401(K) Plans." NBER Working Paper No. 17587.

Bernheim, B. Douglas, and Antonio Rangel. 2009. "Beyond Revealed Preference: Choice-Theoretic Foundations for Behavioral Welfare Economics." Quarterly Journal of Economics 124 (1): 51-104.

Carroll, Gabriel, James Choi, David Laibson, Brigitte Madrian, and Andrew Metrick. 2009. "Optimal Defaults and Active Decisions." Quarterly Journal of Economics 124,1639-1674.

Centers for Medicare and Medicaid Service, "Impact of Reassignment in the Part D Program on Health Outcomes," June 11, 2009. http://www.cms.gov/PrescriptionDrugCovGenIn/Downloads/ReassignmentOutcomes.pdf

Chetty, Raj, John Friedman, Tore Olsen, and Luigi Pistaferri. 2011. "Adjustment Costs, Firm Responses, and Labor Supply Elasticities: Evidence from Danish Tax Records." Quarterly Journal of Economics 126, 749-804.

Chetty, Raj, John Friedman, Soren Leth-Petersen, Torben Nielsen, and Tore Olsen. 2012. "Active vs. Passive Decisions and Crowdout in Retirement Savings Accounts: Evidence from Denmark". NBER Working Paper No. 18565.

Choi, James, David Laibson, Brigitte Madrian, and Andrew Metrick. 2004. "For Better or For Worse: Default Effects and 401(k) Savings Behavior." David Wise, editor. Perspectives in the Economics of Aging. Chicago, IL: University of Chicago Press, 81-121.

DellaVigna, Stefano and Ulrike Malmendier. 2004. "Contract Design and Self-Control: Theory and Evidence." Quarterly Journal of Economics 119, 353-402.

Dubé, Jean-Pierre, Günter Hitsch, and Peter Rossi. 2009. "Do Switching Costs Make Markets Less Competitive?." Journal of Marketing Research 46, 435-445. 
Duggan, Mark, Patrick Healy, and Fiona Scott Morton. 2008. "Providing Prescription Drug Coverage to the Elderly: America's Experiment with Medicare Part D." Journal of Economic Perspectives 22, 69-92.

Ericson, Keith M. 2011. "Forgetting We Forget: Overconfidence and Memory." Journal of the European Economic Association 9, 43-60.

Ericson, Keith M. 2014a. "Consumer Inertia and Firm Pricing in the Medicare Part D Prescription Drug Insurance Exchange". American Economic Journal: Economic Policy 6, $38-64$.

Ericson, Keith M. 2014b. "On the Interaction of Memory and Procrastination". Working Paper.

Esteves-Sorenson, Constança, and Fabrizio Perretti. 2012. "Micro-Costs: Inertia in Television Viewing." The Economic Journal 122 (563): 867-902.

Farrell, Joseph, and Klemperer, Paul. 2007. "Coordination and Lock-In: Competition with Switching Costs and Network Effects." Handbook of Industrial Organization, Elsevier, Vol 3, 1967-2072.

Farrell, Joseph, and Carl Shapiro. 1988. "Dynamic Competition with Switching Costs." RAND Journal of Economics 19, 123-137.

Gabaix, Xavier, and David Laibson. 2006. "Shrouded Attributes, Consumer Myopia, and Information Suppression in Competitive Markets." Quarterly Journal of Economics 121, 505-540.

Goda, Gopi Shah, and Colleen Flaherty Manchester. 2013. "Incorporating Employee Heterogeneity into Default Rules for Retirement Plan Selection." Journal of Human Resources 48 (1): 198-235.

Greenstein, S.M. 1993. "Did installed base give an incumbent any (measurable) advantage in federal computer procurement?" RAND Journal of Economics 24, 19-39.

Handel, Benjamin. 2013. "Adverse Selection and Switching Costs in Health Insurance Markets: When Nudging Hurts." American Economic Review, 103 (7), 2643-2682.

Heidhues, Paul, Botond Koszegi, and Takeshi Murooka. 2012. "The Market for Deceptive Products." Working Paper. 
Johnson, Eric J., and Daniel Goldstein. 2003. "Do Defaults Save Lives?" Science 302 (5649): 1338-39.

Lacetera, Nicola, Devin G Pope, and Justin R Sydnor. 2012. "Heuristic Thinking and Limited Attention in the Car Market." American Economic Review 102 (5): 2206-36.

Laibson, David. 1997. "Golden Eggs and Hyperbolic Discounting". Quarterly Journal of Economics 112: 443-477.

Letzler, Robert and Joshua Tasoff. 2012. "Everyone Believes in Redemption: Overoptimism and Nudges". Working Paper.

Madrian, Brigitte and Dennis Shea. 2001. "The Power of Suggestion: Inertia in 401(k) Participation and Savings Behavior." Quarterly Journal of Economics 116, 1149-1187.

Maskin, Eric, and Jean Tirole. 2001. "Markov Perfect Equilibrium: I. Observable Actions." Journal of Economic Theory 100, 191-219.

O’Donoghue, Ted, and Matthew Rabin. 2001. "Choice and Procrastination." Quarterly Journal of Economics 116, 121-160.

Samuelson, William, and Richard Zeckhauser. "Status Quo Bias in Decision Making." Journal of Risk \&3 Uncertainty 1 (1988), 7-59.

Strombom, Bruce, Thomas Buchmueller, and Paul Feldstein. 2002. "Switching Costs, Price Sensitivity and Health Plan Choice." Journal of Health Economics 21 (2002), 89-116.

Summer L, Hoadley J, Hargrave E. 2010. "The Medicare Part D Low-Income Subsidy Program: Experience to Date and Policy Issues for Consideration." Kaiser Family Foundation Brief \#8094.

Taubinsky, Dmitry. 2013. "From Intentions to Actions: A Model and Experimental Evidence of Inattentive Choice", Working Paper.

Taylor, Curtis. "Supplier Surfing: Competition and Consumer Behavior in Subscription Markets." RAND Journal of Economics 34 (2003), 223-246. 


\section{For Online Publication: Web Appendix When Consumers Do Not Make an Active Decision: Dynamic Default Rules and their Equilibrium Effects}

Keith M Marzilli Ericson

\section{A.1 Proof of Propositions in the Text}

Proposition 1. For a given default, a competitive equilibrium exists and takes the following form: each period, firms set introductory prices $p_{\text {initial }}^{*}=c-\frac{\delta}{\eta_{\text {Repeat }}} \frac{D_{\text {repeat }}}{1+\left(1-D_{\text {repeat }}\right)}$ and legacy prices $p_{\text {legacy }}^{*}=c+\frac{1}{\eta_{\text {repeat }}}$. All young consumers purchase a product at an introductory price. Fraction $1-D_{\text {repeat }}$ of old consumers switch to a different product and get an introductory price.

Proof. The repeat demand of old consumers who previously purchased from a firm is a function of $\Delta p=p_{\text {legacy }}-p_{\text {initial }}$. Legacy prices are set by maximizing $\left(p_{\text {legacy }}-c\right) D_{\text {repeat }}(\Delta p)$, giving $p_{\text {legacy }}^{*}=c+\frac{1}{\eta_{\text {repeat }}}$. The zero-profit condition requires that $p_{\text {initial }}$ be defined by $\left[1+\left(1-D_{\text {repeat }}\right)\right]\left(p_{\text {initial }}-c\right)+\delta\left(p_{\text {legacy }}-c\right) D_{\text {repeat }}=0$. Note that the measure of consumers purchasing at the introductory price includes measure 1 of young consumers and $\left(1-D_{\text {repeat }}\right)$ old consumers. This then gives $p_{\text {initial }}^{*}=c-\frac{\delta}{\eta_{\text {Repeat }}} \frac{D_{\text {repeat }}}{1+\left(1-D_{\text {repeat }}\right)}$. Depending on the distributions $G$ and $H$ there may be multiple equilibria having the specified form. At least one such equilibrium exists.

Proposition 2. Under perfect competition, the privately optimal dynamic default is automatic switching if $\int_{0}^{\bar{\lambda}+\Delta p} \omega d G(\omega)<\Delta p \cdot G(\bar{\lambda}+\Delta p)$, and is otherwise automatic renewal.

Proof. We need only consider expected utility when consumers are old, as the introductory price and consumer behavior while young is invariant to a change in the default. Under automatic renewal, utility when old is given by:

$$
E U^{R e}=v-\left[p_{\text {legacy }}-\Delta p(1-\psi) G(\Delta p)+(1-\psi) \int_{0}^{\Delta p} \omega d G(\omega)\right]
$$

since a consumer switches with probability $(1-\psi) G(\Delta p)$, saving $\Delta p$ relative to the legacy price $p_{\text {legacy }}$, but bearing adjustment costs. Similarly, under an automatic switching default, expected second period utility is

$$
E U^{S w}=v-\left[\begin{array}{c}
p_{\text {legacy }}-\Delta p[(1-\psi) G(\Delta p)+\psi G(\bar{\lambda}+\Delta p)] \\
+(1-\psi) \int_{0}^{\Delta p} \omega d G(\omega)+\psi \int_{0}^{\bar{\lambda}+\Delta p} \omega d G(\omega)
\end{array}\right]
$$


since consumers switch 1) if they are attentive and $\Delta p>\omega_{i t}$, or 2) if they are inattentive and $\bar{\lambda}+\Delta p>\omega_{i t}$. Taking the difference, $E U^{S w}>E U^{R e}$ iff $\Delta p \cdot G(\bar{\lambda}+\Delta p)>\int_{0}^{\bar{\lambda}+\Delta p} \omega d G(\omega)$.

Proposition 3. Under perfect competition, the socially optimal dynamic default for the population is automatic switching if $\psi \int_{0}^{\bar{\lambda}+\Delta p_{S w}} \omega d G(\omega)<(1-\psi) \int_{\Delta p_{S w}}^{\Delta p_{R e}} \omega d G(\omega)$, and is otherwise automatic renewal.

Proof. The optimal default from the social welfare perspective simply minimizes adjustment costs borne, since transfers to all consumers are equally weighted and firms make zero profits. (The cost of producing the product $c$ per period and the quantity sold are invariant to the default.) Adjustment costs borne per period under the automatic switching default are equal to

$$
(1-\psi) \int_{0}^{\Delta p_{S w}} \omega d G(\omega)+\psi \int_{0}^{\bar{\lambda}+\Delta p_{S w}} \omega d G(\omega)
$$

since consumer switching behavior is as described in Proposition 2. Similarly, adjustment costs borne under automatic renewal are equal to $(1-\psi) \int_{0}^{\Delta p_{R e}} \omega d G(\omega)$ per period. Hence, adjustment costs are lower under automatic switching if

$$
\psi \int_{0}^{\bar{\lambda}+\Delta p_{S w}} \omega d G(\omega)<(1-\psi) \int_{\Delta p_{S w}}^{\Delta p_{R e}}
$$

as asserted.

Proposition 4. With a monopolist seller, the privately optimal dynamic default for a consumer who enters the market under both defaults is non-purchase iff

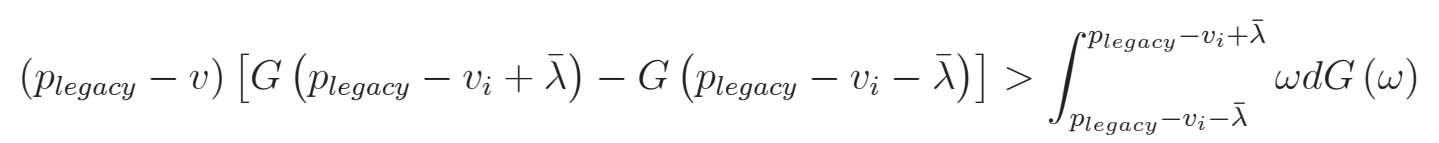

and is otherwise automatic renewal. If the consumer enters the market for only one default, their privately optimal dynamic default is the one under which they enter.

Proof. For the analysis of privately optimal defaults, the prices are constant across defaults. For a consumer who enters the market under both defaults, behavior when young does not depend on the default by assumption. Expected utility when old and attentive is unaffected by the default. Finally, expected utility when old and inattentive is simply $\int_{0}^{\omega_{v_{i} \text { Def }}^{*}}(-\omega) d G(\omega)+\int_{\omega_{v_{i} \text { Def }}^{*}}^{\infty}\left(v-p_{\text {legacy }}\right)$, where $\omega_{v_{i} \text { Def }}^{*}$ is the default-specific renewal threshold defined in the text. Utility under the non-purchase default is higher whenever $\int_{0}^{\omega_{v_{i} N o n}^{*}}(-\omega) d G(\omega)+\int_{\omega_{v_{i} N o n}^{*}}^{\infty}\left(v-p_{\text {legacy }}\right)>\int_{0}^{\omega_{v_{i} R e}^{*}}(-\omega) d G(\omega)+\int_{\omega_{v_{i} R e}^{*}}^{\infty}\left(v-p_{\text {legacy }}\right) d G(\omega)$, which simplifies to the asserted condition. If the consumer purchases under only one default, that default is privately optimal, since it is revealed preferred to not entering the market. 
Proposition 5. With a monopolist seller, the socially optimal dynamic default is nonpurchase iff $\delta \int_{\max \left\{v_{R e}^{*}, v_{N o}^{*}\right\}}^{\infty}[\Delta A t t(v)+\Delta \operatorname{Inatt}(v)] d W(v)>\int_{v_{R e}^{*}}^{v_{N o n}^{*}} N e w^{D e f}(v) d W(v)$, where Def is the default under which more consumers enter the market when young, and is otherwise automatic renewal.

Proof. Social welfare is the total valuation of purchasers, minus the cost of production and adjustment costs. For a given default, this can be decomposed into the welfare of the young and old at each valuation $v$, and then integrated over the distribution of first-period purchasers. Thus, social welfare is: $\int_{v_{D e f}^{*}}^{\infty}(v-c)+\delta\left[\operatorname{Att}^{\text {Def }}(v)+\operatorname{Inatt}^{\text {Def }}(v)\right] d W(v)$, with

$$
A t t^{D e f}(v)=(1-\psi)\left[\int_{0}^{p_{\text {legacy }}^{\text {Def }}-v}(-\omega) d G+\int_{p_{\text {legacy }}^{\text {Def }}-v}^{\infty}(v-c) d G\right]
$$

and

$$
\operatorname{Inatt}^{\text {Def }}(v)=\psi\left[\int_{0}^{\omega_{v_{i} D e f}^{*}}(-\omega) d G+\int_{\omega_{v_{i} \text { Def }}^{*}}^{\infty}(v-c) d G\right] .
$$

When comparing welfare under the defaults, the left-hand side of the condition for optimality integrates over the valuation of consumers who purchase when young under both sets of defaults, leaving just the change in welfare when old; this is decomposed into that for attentive and inattentive consumers with $\operatorname{Att}^{N o}(v)-A t t^{R e}(v)=(1-\psi) \int_{P_{\text {legacy }}^{N o}-v}^{p_{\text {legacy }}^{R e v}}(v-c+\omega) d G$, and $\operatorname{Inatt}^{N o}(v)-\operatorname{Inatt}^{R e}(v)=-\psi\left[\int_{\text {legecy }_{\text {legacy }}^{\text {Re }}-v_{i}-\bar{\lambda}}^{p_{\text {No }}-v_{i}+\bar{\lambda}}(v-c+\omega) d G\right]$. The increase in social welfare under a non-purchase default for type $i$ who purchases when young under both defaults is then $\delta\left[\Delta A t t\left(v_{i}\right)+\Delta \operatorname{Inatt}\left(v_{i}\right)\right]$. The change in social welfare for type $i$ who purchases when young under default Def only is New Def $\left(v_{i}\right)=\left(v_{i}-c\right)\left[1+\delta D_{\text {old }}^{\text {Def }}\left(v_{i}\right)\right]-$ $(1-\psi) \int_{0}^{p_{\text {legacy }}-v_{i}} \omega d G(\omega)-\psi \int_{0}^{\omega_{v_{i}}^{*} \text { Def }} \omega d G(\omega)$, with $D_{\text {old }}^{\text {Def }}\left(v_{i}\right)$ being the repeat demand for type $v$. Then, total change in social welfare from moving to a non-purchase default simply integrates over all the different valuations in the population.

\section{A.2 Appendix: Extension to General Distribution of PFLI and Opt-Out Costs}

This appendix generalizes the discussion in Section 3. I now consider optimal defaults when $\lambda_{i t}$, the tolerable losses from inaction resulting from psychological frictions, is drawn from an arbitrary distribution $H$ that is continuous, bounded and differentiable with p.d.f. $h$. As in Section 3, consumers also draw an adjustment cost $\omega$ from a continuous, bounded and differentiable distribution $G$.

Furthermore, I allow for an "opt-out" cost $\kappa$ that must be borne when a consumer does 
not take the default option, where $\kappa$ is a real resource cost and lowers utility. The opt-out cost $\kappa$ represents the cost of actively expressing preference (e.g. sending back a form), and is distinct from the cost of switching products (e.g. setting up prescription to be billed to a new insurer). Thus, $\kappa$ is borne when people switch under an automatic renewal default, and when people do not switch under an automatic switching default. The cost $\kappa$ acts similarly to $\lambda$ in how it affects consumer behavior: it increases the likelihood of taking the default. However, it affects utility differently than $\lambda$, as it directly affects an individual's WTP for different defaults; it can be distinguished from $\lambda$ using the choice experiments described in Section 2.4. Intuitively, $\kappa$ creates an additional motivation to choose a default that matches the most likely action: if most consumers switch products each period, then an automatic switching default might raise welfare by saving them the cost of opting out of the default.

When the default is automatic renewal, consumers switch if the gain to doing so, net of adjustment costs, exceeds $\lambda_{i t}+\kappa$, the psychological friction and the real cost of opting out of the default. This occurs with probability $q_{R e} \equiv \int_{0}^{\infty} H(\Delta p-\omega-\kappa) d G(\omega)$ : the probability that $\Delta p-\omega_{i t}>\lambda_{i t}+\kappa$, integrated over draws of $\omega$. Similarly, when the default is automatic switching, attentive consumers always switch when $\Delta p-\omega_{i t}>-\kappa$, since they compare the gain of switching to paying $\kappa$ if they opt out of the default. However, when $\lambda>0$, they also switch so long as $\omega_{i t}-\Delta p-\kappa<\lambda_{i t}$, since they are willing to tolerate a loss of $\lambda$ to stay with the default of switching. Thus, the probability they switch is given by $q_{S w} \equiv 1-\int_{0}^{\infty} H(\omega-\Delta p-\kappa) d G(\omega)$.

Now, we have the analogues of Propositions 2 and 3. Proposition A.1 again shows that the privately optimal default for an individual consumer weighs the price savings against the increased adjustment costs and opt-out costs borne. Similarly, Proposition A.2 shows that the socially optimal default for the entire population is the default that minimizes adjustment costs and opt-out costs.

Proposition A.1. Under the competitive equilibrium setup with $\kappa>0$ and distribution $H$ of $\lambda$, the privately optimal dynamic default is automatic switching if

$$
\kappa\left[\left(1-q_{S w}\right)-q_{R e}\right]+\int_{0}^{\infty} \int_{\Delta p-\lambda-\kappa}^{\Delta p+\lambda+\kappa} \omega d G(\omega) d H(\lambda)<\Delta p\left(q_{S w}-q_{R e}\right)
$$

and is otherwise automatic renewal.

Proof. The proof follows that of Proposition 2. Under automatic renewal, expected total costs in the second period are given by

$$
E T C_{R e}=\kappa q_{\text {Re }}+p_{\text {legacy }}\left(1-q_{\text {Re }}\right)+p_{\text {initial }}\left(q_{R e}\right)+\int_{0}^{\infty} \int_{0}^{\Delta p-\kappa-\lambda} \omega d G(\omega) d H(\lambda)
$$


where the last term is adjustment costs borne. For each value of $\lambda$, the adjustment costs borne are those between $\omega=0$ and $\omega=\Delta p-\lambda-\kappa$. Similarly, under automatic switching, expected total price, adjustment, and opt-out costs in in the second period are given by

$$
E T C_{S w}=\kappa\left(1-q_{S w}\right)+p_{\text {legacy }}\left(1-q_{\text {Sw }}\right)+p_{\text {initial }}\left(q_{S w}\right)+\int_{0}^{\infty} \int_{0}^{\Delta p+\lambda+\kappa} \omega d G(\omega) d H(\lambda)
$$

where again, the last term is adjustment costs borne. For each value of $\lambda$, we take the integral of adjustment costs from $\omega=0$ to $\omega=\Delta p+\lambda+\kappa$, since the latter adjustment cost gives the maximal tolerable loss from switching. Now, automatic switching is privately optimal if $E T C_{S w}<E T C_{R e}$, which requires

$$
\kappa\left[\left(1-q_{S w}\right)-q_{R e}\right]+\int_{0}^{\infty} \int_{\Delta p-\lambda-\kappa}^{\Delta p+\lambda+\kappa} \omega d G(\omega) d H(\lambda)<\Delta p\left(q_{S w}-q_{R e}\right)
$$

as asserted.

Proposition A.2. Define $z=\frac{\Delta p_{R e}-\Delta p_{S w}-2 \kappa}{2}$. Under the competitive equilibrium setup with $\kappa>0$ and distribution $H$ of $\lambda$, the socially optimal dynamic default is automatic switching if

$$
\kappa\left[\left(1-q_{S w}\right)-q_{R e}\right]+\int_{z}^{\infty} \int_{\Delta p_{R e}-\lambda-\kappa}^{\Delta p_{S w}+\lambda+\kappa} \omega d G(\omega) d H(\lambda)<\int_{0}^{z} \int_{\Delta p_{S w}+\lambda+\kappa}^{\Delta p_{R e}-\lambda-\kappa} \omega d G(\omega) d H(\lambda)
$$

and is otherwise automatic renewal.

Proof. The proof follows that of Proposition 3: the socially optimal default minimizes real adjustment costs and opt-out costs borne. Using the logic of Proposition A.1, note that total adjustment costs and opt-out costs borne under automatic renewal are given by

$$
\int_{0}^{\infty} \int_{0}^{\Delta p_{R e}-\lambda-\kappa} \omega d G(\omega) d H(\lambda)+\kappa q_{R e}
$$

where $\Delta p_{R e}$ is the equilibrium introductory v. legacy price differential between, given the automatic renewal default. Similarly, adjustment costs and opt-out costs borne under automatic switching are given by

$$
\int_{0}^{\infty} \int_{0}^{\Delta p_{S w}+\lambda+\kappa} \omega d G(\omega) d H(\lambda)+\kappa\left(1-q_{S w}\right)
$$

Note that when $\Delta p_{S w} \geq \Delta p_{R e}$, total adjustment costs borne are certainly higher under automatic switching, but opt-out costs may be lower. In general, automatic switching is 
optimal if total adjustment and opt-out costs are higher under automatic renewal

$$
\int_{0}^{\infty}\left[\int_{0}^{\Delta p_{R e}-\lambda-\kappa} \omega d G(\omega)-\int_{0}^{\Delta p_{S w}+\lambda+\kappa} \omega d G(\omega)\right] d H(\lambda)+\kappa\left[q_{R e}-\left(1-q_{S w}\right)\right]>0
$$

Now, we can break the integrals apart, noting that $\Delta p_{R e}-\lambda-\kappa>\Delta p_{S w}+\lambda+\kappa$ when $z \equiv \frac{\Delta p_{R e}-\Delta p_{S w}-2 \kappa}{2}>\lambda$. Hence we have automatic switching optimal when

$$
\int_{0}^{z} \int_{\Delta p_{S w}+\lambda+\kappa}^{\Delta p_{R e}-\lambda-\kappa} \omega d G(\omega) d H(\lambda)>\int_{z}^{\infty} \int_{\Delta p_{R e}-\lambda-\kappa}^{\Delta p_{S w}+\lambda+\kappa} \omega d G(\omega) d H(\lambda)+\kappa\left[\left(1-q_{S w}\right)-q_{R e}\right]
$$

as asserted. It can easily be seen that this expression simplifies to the condition in Proposition 3: with $\lambda=\bar{\lambda}$ with probability $\psi$ and otherwise zero, it becomes $\psi \int_{\Delta p_{S w}+\bar{\lambda}+\kappa}^{\Delta p_{R e}-\bar{\lambda}-\kappa} \omega d G(\omega)>$ $(1-\psi) \int_{\Delta p_{R e}-\kappa}^{\Delta p_{S w}+\kappa} \omega d G(\omega)+\kappa\left[\left(1-q_{S w}\right)-q_{R e}\right]$. Setting $\kappa=0$, noting that $\Delta p_{R e}-\bar{\lambda}<0$ by assumption, and multiplying by -1 , we have $\psi \int_{0}^{\Delta p_{S w}+\bar{\lambda}} \omega d G(\omega)<(1-\psi) \int_{\Delta p_{S w}}^{\Delta p_{R e}} \omega d G(\omega)$, as asserted.

\section{A.3 Appendix: Generalization to Infinite Horizon}

Now, let consumers live more than two-periods: let consumers have a constant hazard $\rho \in(0,1)$ of dying each period, so that fraction $1-\rho$ of the population survives from the last period. Let population size be constant, as each period measure $\rho$ of new consumers that are unattached to any product enter the population. As before, consumers discount future utility by $\delta<1$ each period, in addition to the discounting that results from the probability of death. Each period, a consumer receives an i.i.d. draws of $\omega_{i t}$ from $G$ and $\lambda_{i t}$ from $H .{ }^{23}$ Define $D_{\text {repeat }}\left(p-p_{\text {initial }}\right)$ as the repeat demand of measure one of consumers at a firm charging a legacy price $p$ in market in which the lowest price is $p_{\text {initial }}$; that is, if a firm has measure $s$ potential repeat customers, the measure of customers who actually buy again from the firm is $s \cdot D_{\text {repeat }}\left(p-p_{\text {initial }}\right)$. As before, $\eta_{\text {repeat }}=\frac{-D_{\text {repeat }}^{\prime}}{D_{\text {repeat }}}$

I assume that there $N \geq 2$ firms in the market. Firms can distinguish between repeat customers from last period and new customers, but cannot observe a consumer's entire purchase history. Because firms are involved in an infinitely-repeated game, many possible collusive equilibria may exist. I consider a Markov-perfect equilibrium (Maskin and Tirole 2001) in which firms' prices cannot depend on other firms' histories. Proposition A.3 shows that a simple invest-then-harvest equilibrium exists.

\footnotetext{
${ }^{23}$ The i.i.d. assumption implies that there are no persistent heterogeneity in consumers' propensities to switch. This assumption substantially simplifies the calculation of equilibrium, but could be relaxed. In the presence of persistent heterogeneity in switching costs, firms would set price taking into account that the mix of individuals that would purchase is endogenous to the price.
} 
Proposition A.3. A pure-strategy Markov-perfect equilibrium exists and takes the following form. Firms set introductory price $p_{\text {initial }}$, and price for previous period purchasers $p_{\text {legacy, }}$ with prices given by $p_{\text {initial }}=c-\delta \frac{V\left((1-\rho) s_{0}\right)}{s_{0}}$, and $p_{\text {legacy }}=c+\frac{1}{\eta_{\text {repeat }}}-\delta(1-\rho) V^{\prime}(s)$. The price differential $\Delta p \equiv p_{\text {legacy }}-p_{\text {initial }}=\frac{1}{\eta_{\text {repeat }}}$. Each firm receives new purchasers of measure $s_{0}=\frac{1}{N}\left[\rho+(1-\rho)\left(1-D_{\text {repeat }}(\Delta p)\right)\right]$ each period. The value of a firm with measure $s$ of customers is $V(s)=s \frac{D_{\text {repeat }}}{\eta_{\text {repeat }}}$.

Proof. I show the proposed equilibrium exists by construction. Take the proposed value function for a firm with market share $s$ :

$$
V(s)=s \frac{\left[D_{\text {repeat }}(\Delta p)\right]^{2}}{-D_{\text {repeat }}^{\prime}(\Delta p)}
$$

where we define $\Delta p^{*}=\frac{D_{\text {repeat }}\left(\Delta p^{*}\right)}{-D_{\text {repeat }}^{\prime}\left(\Delta p^{*}\right)}=\frac{1}{\eta_{\text {repeat }}}$. Note that $\Delta p^{*}$ does not depend on either $p_{\text {legacy }}$ or $p_{\text {initial directly. }}$

This value function is linear in $s$ and hence has a constant derivative with respect to $s$. Since the value function of a firm with a positive customer base is given by

$$
V(s)=\max _{p} s(p-c)\left[D_{\text {repeat }}\left(p-p_{\text {initial }}\right)\right]+\delta V\left(s(1-\rho)\left[D_{\text {repeat }}\left(p-p_{\text {initial }}\right)\right]\right)
$$

the first order condition determining the optimal legacy price is

$$
p_{\text {legacy }}^{*}=c+\frac{D_{\text {repeat }}\left(\Delta p^{*}\right)}{-D_{\text {repeat }}^{\prime}\left(\Delta p^{*}\right)}-\delta(1-\rho) V^{\prime}(s)
$$

This does not depend on $s$ given the linearity of $V$. Substituting in for $V^{\prime}$ and $\eta$ gives

$$
p_{\text {legacy }}^{*}=c+\frac{D_{\text {repeat }}\left(\Delta p^{*}\right)}{-D_{\text {repeat }}^{\prime}\left(\Delta p^{*}\right)}\left[1-\delta(1-\rho)\left[D_{\text {repeat }}\left(\Delta p^{*}\right)\right]\right]
$$

which defines $p_{\text {legacy. }}$. It is easy to see that this pricing strategy yields the proposed value function, as

$$
\begin{aligned}
V(s) & =s\left(p_{\text {legacy }}-c\right)\left[D_{\text {repeat }}\left(\Delta p^{*}\right)\right]\left\{1+\delta(1-\rho)\left[D_{\text {repeat }}\left(\Delta p^{*}\right)\right]+\delta^{2}(1-\rho)^{2}\left[D_{\text {repeat }}\left(\Delta p^{*}\right)\right]^{2}+\ldots\right\} \\
& =s\left(p_{\text {legacy }}-c\right)\left[D_{\text {repeat }}\left(\Delta p^{*}\right)\right] \frac{1}{1-\delta(1-\rho)\left[D_{\text {repeat }}\left(\Delta p^{*}\right)\right]}
\end{aligned}
$$

Now, consider competition for new customers. The market is competitive, and so firms compete away future profits with the initial price. The zero-profit condition gives 
$s_{0}\left(p_{\text {initial }}-c\right)=-\delta V\left((1-\rho) s_{0}\right)$, or by the linearity of $V$ :

$$
\begin{aligned}
p_{\text {initial }}^{*} & =c-\delta(1-\rho) V^{\prime}(s) \\
& =c-\delta(1-\rho) \frac{\left[D_{\text {repeat }}\left(\Delta p^{*}\right)\right]^{2}}{D_{\text {repeat }}^{\prime}\left(\Delta p^{*}\right)}
\end{aligned}
$$

It is easily checked that these values of $p_{\text {initial }}^{*}$ and $p_{\text {legacy }}^{*}$ satisfy the definition of $\Delta p^{*}$.

Now I show that neither type of firm has an incentive to deviate from the proposed strategy. First, note that the optimal strategy for setting a legacy price depends solely on a firms' last period purchasers and $p_{\text {initial }}$, as repeat demand is a function only of the plan's own price and the lowest price in the market, which will be an introductory price. Then, consider deviations to alternative introductory prices $p^{\prime}$. If $p^{\prime}>p_{\text {initial }}$, the firm gets no new customers, and makes zero profit. If $p^{\prime}<p_{\text {initial }}$, the firm makes negative discounted profits. Hence there are no profitable deviations for introductory prices.

Finally, consider deviations to alternative legacy prices. Given $p_{\text {initial }}, p_{\text {legacy }}$ is defined as profit maximizing and so there is no incentive to deviate to any other legacy price $p_{\text {legacy }}^{\prime}>$ $p_{\text {initial }}$. If $p_{\text {legacy }}^{\prime}<p_{\text {initial }}$, the firm makes negative discounted profits, just as a firm setting an introductory price below $p_{\text {initial }}$ would. The other potential deviation is to $p_{\text {legacy }}^{\prime}=p_{\text {initial }}$. But this would give zero profits: such a firm would get higher enrollment $s^{\prime}>s_{0}$ since it would attract unattached consumers as well as keep all its own enrollees. But the value of such a firm is $s^{\prime}\left(p_{\text {initial }}-c\right)+\delta V\left((1-\rho) s^{\prime}\right)=0$ (assuming future optimal action) which is invariant to $s^{\prime}$ and equal to zero by construction. Hence the proposed $\left\{p_{\text {initial }}, p_{\text {legacy }}\right\}$ strategy is an equilibrium.

Proposition A.4. If the equilibrium in Proposition A.3 obtains, privately optimal and socially optimal defaults are determined by Propositions 2 and 3, respectively.

When consumers enter the market, they face price $p_{\text {initial }}$.In period 2 they draw $\omega$ from $G$, and $\lambda$ from $H$. The consumer faces the same decision in this period as a consumer would in case where consumers lived only two periods: their result is affected by the default and $\lambda$, if they switch they pay $p_{\text {legacy }}$ but bear $\omega_{i t}$, if they renew they pay $p_{\text {legacy }}$. Regardless of whether the consumer switches or renews, they will face the same decision in period 3 (with a new draw of $\lambda, \omega)$, as prices only vary based on whether the consumer has newly switched or purchased in the previous period. 